\title{
Cardiac autonomic function, cardiovascular risk and physical activity in adolescents
}

\begin{tabular}{|c|c|}
\hline Journal: & International Journal of Sports Medicine \\
\hline Manuscript ID & IJSM-01-2017-6118-pb \\
\hline Manuscript Type: & Physiology \& Biochemistry \\
\hline Key word: & $\begin{array}{l}\text { Cardiovascular disease, heart rate variability, CVD risk factors, risk factor } \\
\text { gap }\end{array}$ \\
\hline Abstract: & $\begin{array}{l}\text { The aims of this study were to investigate in adolescents: } 1 \text { ) the } \\
\text { relationships of physical activity (PA) and cardiorespiratory fitness (CRF) to } \\
\text { traditional CVD risk factors, rest and recovery autonomic function; and } 2 \text { ) } \\
\text { whether autonomic function strengthens the associations between PA, CRF } \\
\text { and CVD risk. Fifty-four ( } 22 \text { girls) adolescents had traditional CVD risk } \\
\text { factors, rest and recovery autonomic function evaluated. CRF was } \\
\text { measured using a steep ramp cycle test and PA was assessed with } \\
\text { accelerometers. Resting HRV (and RMSSD30) and heart rate recovery } \\
\text { (T30, HHRT) were used. Clustered traditional (CVDRtrad) and autonomic } \\
\text { (CVDRauto) risk scores were created and added to form a composite } \\
\text { clustered CVD risk score (CVDRcom). PA and CRF were significantly and } \\
\text { negatively associated to traditional CVD risk factors. Moderate (MPA) and } \\
\text { vigorous (VPA) were positively related to resting RMSSD, and negatively } \\
\text { related to T30 and HHRT (all P<0.05). RMSSD30 recovered faster in the } \\
\text { high compared to low median split for VPA. Stronger associations for } \\
\text { CVDRcom compared to CVDRtrad were observed for MPA (CVDRcom: } \\
\text { r } 2=0.32, \mathrm{P}=<0.001 ; \text { CVDRtrad: } r 2=0.17, \mathrm{P}=0.002 \text { ), and VPA (CVDRcom: } \\
\text { r } 2=0.18, \mathrm{P}=0.001 \text {; CVDRtrad: } \mathrm{r} 2=0.06, \mathrm{P}=0.08 \text { ). These findings } \\
\text { strengthen the proposed additional beneficial effects of PA on autonomic } \\
\text { function above traditional CVD risk factors. }\end{array}$ \\
\hline
\end{tabular}




\title{
Cardiac autonomic function, cardiovascular risk and physical activity in adolescents
}

\begin{abstract}
The aims of this study were to investigate in adolescents: 1) the relationships of physical activity (PA) and cardiorespiratory fitness (CRF) to traditional CVD risk factors, rest and recovery autonomic function; and 2) whether autonomic function strengthens the associations between PA, CRF and CVD risk. Fifty-four (22 girls) adolescents had traditional CVD risk factors, rest and recovery autonomic function evaluated. CRF was measured using a steep ramp cycle test and PA was assessed with accelerometers. Resting HRV (and RMSSD 30 ) and heart rate recovery $\left(\mathrm{T}_{30}, \mathrm{HHR} \tau\right)$ were used. Clustered traditional $\left(\mathrm{CVDR}_{\text {trad }}\right)$ and autonomic $\left(\mathrm{CVDR}_{\text {auto }}\right)$ risk scores were created and added to form a composite clustered CVD risk score $\left(\mathrm{CVDR}_{\text {com }}\right)$. PA and CRF were significantly and negatively associated to traditional CVD risk factors. Moderate (MPA) and vigorous (VPA) were positively related to resting RMSSD, and negatively related to $\mathrm{T}_{30}$ and $\mathrm{HHR} \tau$ (all $P<0.05$ ). $\mathrm{RMSSD}_{30}$ recovered faster in the high compared to low median split for VPA. Stronger associations for $\mathrm{CVDR}_{\text {com }}$ compared to $\mathrm{CVDR}_{\text {trad }}$ were observed for MPA $\left(\mathrm{CVDR}_{\mathrm{com}}: \mathrm{r}^{2}=0.32, P=<0.001 ; \mathrm{CVDR}_{\text {trad }}: \mathrm{r}^{2}=0.17\right.$, $P=0.002)$, and VPA $\left(\mathrm{CVDR}_{\text {com }}: \mathrm{r}^{2}=0.18, P=0.001 ; \mathrm{CVDR}_{\text {trad }}: \mathrm{r}^{2}=0.06, P=0.08\right)$. These findings strengthen the proposed additional beneficial effects of PA on autonomic function above traditional CVD risk factors.
\end{abstract}

Key-words: Cardiovascular disease, heart rate variability, CVD risk factors, risk factor gap 


\section{Introduction}

The pathobiological process of atherosclerosis starts during childhood and is related to 'traditional' cardiovascular disease (CVD) risk factors such as blood lipids, blood pressure (BP) and body composition [3]. Physical activity (PA) and cardiorespiratory fitness (CRF) confer CVD risk reduction during childhood by modifying individual or clustered CVD risk factors [18]. However, in adults the summed improvements in traditional CVD risk factors accounts for $\sim 60 \%$ of the reduction in CVD risk [24], meaning there is a $40 \%$ 'risk factor gap' in the explanation of PA benefits [19]. The autonomic and arterial systems have been proposed as components of the risk factor gap and may be considered as 'novel' risk factors [19]. While arterial function has recently been added to a clustered score of traditional CVD risk factors in an attempt to improve the associations between PA and CVD risk in children [14], the influence of autonomic function above traditional CVD risk factors is unknown.

Assessment of cardiac autonomic function by measuring rest and recovery HRV as well as heart rate recovery (HRR) provides distinct and complementary information [11]. While positive relationships between PA and CRF with resting HRV have been demonstrated in youth $[9,16,27]$, further understanding about the potential relationships of PA and CRF to cardiac autonomic function during recovery following exercise is needed. Similarly, the effects of PA intensity on HRV and HRR is not clear. In adolescents, one study reported positive effects for moderate to vigorous (MVPA) but not VPA [27], whereas in another study with pre-adolescents, VPA but not MPA, presented stronger effects [9]. However, none of these studies measured cardiac autonomic recovery following exercise nor combined measures of cardiac autonomic function with traditional CVD risk factors.

The aims of this study were: 1) to investigate the relationship of PA intensity and CRF to traditional CVD risk factors, as well as novel CVD risk factors using measurements of autonomic function at rest and recovery; and 2) to investigate whether adding autonomic 
function measures to a clustered score of traditional CVD risk factors strengthens the associations between PA, CRF and CVD risk.

\section{Methods}

Participants

Participants were recruited from two secondary schools in the South West of England. The volunteers were informed about the study via an assembly and study information sheets were distributed. A flow diagram of the recruitment process with the final number of participants included in the study is presented in Figure 1. Participant descriptive data are presented in Tables 1 and 2. Exclusion criteria included an existing musculoskeletal injury, presence of cardiometabolic disease, taking medications, and showing any contraindications to exercise. Before the study commenced, all participants and their parents/guardians provided written assent and consent, respectively. The study received ethics approval from the institutional Ethics Committee (Ref No: 141022/B/07).

\section{Study design}

This is a cross-sectional study where participants completed three visits to a school-based laboratory over a one-week period as follows:

Visit 1: Participants had stature, body mass, sitting height, and waist circumference (WC) measured followed by triceps and subscapular skinfolds assessment using standard procedures. Peak height velocity (PHV) was used as an indicator of somatic maturity [23] and participants were classified as pre ( -1 year), circa $(-1$ to +1 year), or post $(+1$ year) PHV. Body fat percentage $(\% \mathrm{BF})$ was obtained using validated age and sex-specific equations from skinfold measures [30]. 
Visit 2: Participants reported to the laboratory in a fasted state ( $>10$ hours) and lay supine for 10-min. Resting heart rate was recorded followed by measurements of BP. Next, a fingertip capillary blood sample was collected to measure lipid profile and glucose concentration.

Visit 3: A cycle test to exhaustion was performed to determine CRF. Following exhaustion, participants sat for 10-min for assessment of HRR. At the end of this session, participants were given an accelerometer and instructed to wear the device for seven consecutive days for PA measurements.

\section{Autonomic function}

A 10-min resting period of heart rate measurements (Polar Team2, Kempele, Finland) obtained during the second visit was used to calculate HRV. Participants were asked to pace their breathing frequency at 12 cycles per minute using a metronome. Data were downloaded and error correction conducted in the software polar ProTrainer 5. No files presented more than $3 \%$ of error. Data were then transferred into Kubios v 2.2 (Biosignal Analysis and Medical Imaging Group at the Department of Applied Physics, University of Kuopio, Kuopio, Finland) to calculate time and frequency domain of HRV. The final 5 min period of the data was filtered with a smooth-priors filter and used to calculate HRV. The time domain index obtained to reflect the vagal activity was the RMSSD (square root of the mean of the sum of the squares of differences between adjacent RR intervals). For the frequency domain, a Fast Fourier Transformation was applied and the area under the low (LF: $0.04-0.15 \mathrm{~Hz}$ ) and high frequency (HF: 0.15 to $0.50 \mathrm{~Hz}$ ) bands calculated in absolute $\left(\mathrm{ms}^{2}\right)$ and normalized units $(\mathrm{nu})$, as well as a ratio $(\mathrm{LF} / \mathrm{HF})$. The HF band reflects vagal modulations while the LF band indicates both sympathetic and parasympathetic influences. All data collection and analyses procedures were conducted in accordance with published guidelines [31]. HRV measurements performed by our group have been demonstrated to be reliable (CV: 17.6\%) $[5]$. 
Heart rate recovery after the cycle test was recorded (Polar Team2, Kempele, Finland) and downloaded for later analysis. The same procedures of error correction for the HRV data were applied. The time decay of the heart rate in the first $30 \mathrm{~s}\left(\mathrm{~T}_{30}\right)$ post exercise was measured as an index of vagal reactivation [17]. A single-exponential function was also used to model HRR during the $10 \mathrm{~min}$ period and the time constant $(\tau)$ was used as an indicator of the HRR. For this purpose, beat-by-beat heart rate was interpolated into $1 \mathrm{~s}$. The $\operatorname{HRR} \tau$ is known to be dependent of both parasympathetic reactivation and sympathetic withdrawal [8]. During recovery, the RMSSD 30 was obtained by calculating RMSSD every 30 s throughout the full 10 -min recovery period. $\mathrm{RMSSD}_{30}$ was then transformed into a natural logarithm and a median filter was applied [15]. $\mathrm{RMSSD}_{30}$ is known to reflect the time course of the vagal reactivation after exercise.

\section{Traditional cardiovascular disease risk factors}

Blood pressure was measured three times after the 10 min resting period (A\&D Medical Co., LTD, Japan). The average of the two closest systolic and diastolic blood pressure values was retained for analysis and mean arterial pressure (MAP) calculated. The observed coefficient of variation between the measurements of systolic and diastolic BP were all $<4 \%$. Capillary blood samples were used to determine total cholesterol (TC), high-density lipoprotein (HDL), TAG and glucose $\left(\right.$ CardioChek $^{\circledR}$ PA, PTS Diagnostics, USA). All measurements were performed in duplicate and the average value retained for analysis. The observed $\% \mathrm{CV}$ were 5.1, 5.7, 7.4 and $4.3 \%$ for TC, HDL, TAG and glucose, respectively.

\section{Cardiorespiratory fitness}

Peak oxygen uptake (peak $\mathrm{VO}_{2}$ ) was estimated using a validated steep ramp test performed on an electromagnetic brake cycle ergometer (Lode, The Netherlands) [6]. After three minutes of warm-up at $25 \mathrm{~W}$, participants started the test, which consisted of a predetermined increment in work-rate per minute. The work-rate increments were chosen according to 
participant stature: $60 \mathrm{~W}$ if $<120 \mathrm{~cm}, 90 \mathrm{~W}$ if between 120 and $150 \mathrm{~cm}$, and $120 \mathrm{~W}$ if $>150$ $\mathrm{cm}$. The peak power (W) obtained at the end of the ramp test was used to estimate peak $\mathrm{VO}_{2}$ in $\mathrm{mL} \cdot \mathrm{min}^{-1}$. Participants were asked to maintain a pedalling frequency of $80 \mathrm{rpm}$. The protocol ended when participants dropped the pedalling frequency for $5 \mathrm{~s}$ below $60 \mathrm{rpm}$ despite strong verbal encouragement. Maximal effort was considered when participants showed subjective signs of intense effort (e.g., unsteady cycling, sweating, and clear unwillingness to continue despite encouragement). This method has been shown to have strong $\left(\mathrm{R}^{2}=0.92\right)$ criterion-related validity with directly measured CRF [6]. CRF was subsequently normalised for body mass using a ratio standard $\left(\mathrm{mL} \cdot \mathrm{kg}^{-1} \cdot \mathrm{min}^{-1}\right)$ and an allometric method. The latter was calculated from the sample specific exponent $(\beta=0.58)$ obtained from log-linear regression to allometrically scale CRF for body mass.

\section{Physical activity}

Habitual PA was measured using a wrist-worn accelerometer (GENEAciv, Activinsights Ltd, UK). The device was set to record the activities for seven consecutive days at a frequency of $100 \mathrm{~Hz}$ starting in the morning following the third visit. Participants were instructed to wear the device on their non-dominant wrist, including during sleeping hours and water activities. The device was then retrieved and the raw acceleration data transformed into epochs of $60 \mathrm{~s}$ using specific software. The $60 \mathrm{~s}$ epoch files were then used to calculate the time spent performing sedentary time (ST) and light (LPA), moderate (MPA) and vigorous (VPA) PA using validated cut-off points [26]. Participants were included in the final analysis with a minimum of three days with $>12 \mathrm{~h}$ per day of wear time [28].

\section{Statistical analyses}

All data are presented as mean and SD unless otherwise stated. Normality of distribution was checked using Shapiro Wilk's test and skewed data were transformed prior to analysis. A clustered traditional CVD risk score $\left(\mathrm{CVDR}_{\text {trad }}\right)$ was calculated as the sum of the following 
sex-specific standardized z-scores: fasted glucose, fasted triglycerides (TAG), fasted highdensity lipoprotein (HDL), \%BF and blood pressure ([SBP+DBP]/2) [13]. A clustered autonomic risk score $\left(\mathrm{CVDR}_{\text {auto }}\right)$ was created by adding the sex-specific standardized $\mathrm{z}$ scores of resting $\mathrm{RMSSD}, \mathrm{T}_{30}$ and $\operatorname{HRR} \tau$. Z-scores were inverted when appropriate. In order to explore the effects of PA, ST and CRF beyond the traditional CVD risk factors, the $\mathrm{CVDR}_{\text {trad }}$ was combined to the $\mathrm{CVDR}_{\text {auto }}$ to produce a composite CVD risk score $\left(\mathrm{CVDR}_{\text {com }}\right)$. This is in accordance with a recent study that has included novel CVD risk factors into a composite CVD risk score [14].

Separate linear regressions were performed for PA intensities, ST and CRF as the predictor variables. For this purpose, a base model adjusting for sex and maturation was created and the predictors inserted separately. The outcome variables included were: the traditional CVD risk-factors (BMI, \%BF, WC, MAP, TC, HDL, TAG and glucose), non-traditional CVD riskfactors (HRV and $\mathrm{HHR}$ ) and the clustered CVD risk scores $\left(\mathrm{CVDR}_{\text {trad, }} \mathrm{CVDR}_{\text {auto }}\right.$ and $\left.\mathrm{CVDR}_{\text {com }}\right)$. The following variables were log transformed prior to entry into the model: VPA, RMSSD, $\mathrm{T}_{30}, \mathrm{HRR} \tau, \mathrm{HDL}, \mathrm{WC}, \mathrm{BMI}$ and TAG. \%BF did not present a significant relationship to the outcome variables after adjusting for PA/CRF and was not included as a covariate.

In order to test the effects of PA intensities and CRF on the time course of parasympathetic reactivation as measured by the $\mathrm{RMSSD}_{30}$, participants were divided into groups below and above the sex-specific median split for PA intensities and CRF. Median splits were chosen aiming to create equal sample sizes between the CRF groups as well as no thresholds are available in the literature for the allometric scaled CRF used in the present investigation. Repeated measures ANCOVA controlling for sex and maturation were used to examine a 
time ( 0 to $600 \mathrm{~s}$ ) by group (above or below median split) interaction effect for $\mathrm{RMSSD}_{30}$. The alpha level was set at 0.05 for all analyses which were performed using SPSS version 22 .

\section{Results}

Traditional CVD risk factors

Regression coefficients for PA intensities, ST, CRF and traditional CVD risk factors after adjusting for sex and maturation are presented in Table 3. ST and LPA were not significantly associated to any of the traditional CVD risk factors. By contrast, MPA was significantly and negatively associated to BMI, \%BF, WC and MAP. VPA was significantly and negatively associated to $\% \mathrm{BF}$. Both ratio and allometric scaled $\mathrm{CRF}$ were significantly and negatively associated to BMI, \%BF and WC. However, the associations between allometric scaled CRF and the body composition variables were weaker compared to the ratio scaled CRF.

\section{Non-traditional CVD risk factors}

Regression coefficients for the PA intensities, CRF and non-traditional risk factors after adjusting for sex and maturation are presented in Table 3. ST, LPA and CRF (ratio standard and allometrically scaled) were not significantly related to any of the rest or recovery autonomic indices. Both MPA and VPA were significantly and positively related to RMSSD and significantly and negatively related to $\operatorname{HRR} \tau$ and $\mathrm{T}_{30}$. The time course of parasympathetic reactivation using the $\mathrm{RMSSD}_{30}$ is presented in Figure 2. There was no group (below vs. above) by time interaction for ST, LPA, MPA, or CRF for $\operatorname{RMSSD}_{30}$ (all $P>0.05$ ). In contrast, there was a group by time interaction $(P=0.01)$ for VPA, with the above the median group presenting a higher $\mathrm{RMSSD}_{30}$ after the first $60 \mathrm{~s}$ of recovery after exercise (all $P<0.05)$.

\section{Clustered CVD risk scores}

Regression coefficients for the PA intensities, CRF and the CVD risk scores after adjusting for sex and maturation are presented in Table 3. ST time and LPA were not significantly 
related to any of the clustered CVD risk scores. MPA was significantly and negatively associated to $\mathrm{CVDR}_{\text {trad, }} \mathrm{CVDR}_{\text {auto }}$ and $\mathrm{CVDR}_{\text {com. }}$ VPA was significantly and negatively associated to $\mathrm{CVDR}_{\text {auto }}$ and $\mathrm{CVDR}_{\text {com }}$, but not with $\mathrm{CVDR}_{\text {trad }}(P=0.08)$. While ratio scaled CRF was negatively related to $\mathrm{CVDR}_{\text {trad, }}$ allometrically-scaled CRF was not associated to any of the clustered CVD risk scores. After combining $\mathrm{CVDR}_{\text {trad }}$ and $\mathrm{CVDR}_{\text {auto }}$ to form $\mathrm{CVDR}_{\text {com }}$ the coefficient of determination increased from 17 to $32 \%$ and 6 to $18 \%$ for MPA and VPA, respectively.

\section{Discussion}

The key findings of the present investigation were: 1) MPA and VPA were related to traditional CVD risk factors, as well as rest and recovery autonomic function, 2) Girls and boys preforming VPA above the median split presented faster $\mathrm{RMSSD}_{30}$; 3) MPA and VPA were strongly and negatively related to CVD risk when rest and recovery autonomic indices were added to the traditional CVDR score; and 4) CRF was only significantly and negatively related to traditional CVD risk score, however, when allometrically scaled the significant relationship disappeared.

In the current investigation, ST and LPA were not significantly related to the health outcomes which corroborates with previous literature [13], and supports the focus of current PA guidelines on time spent performing MVPA to promote CVD health in adolescents. Both MPA and VPA were negatively associated to \%BF highlighting the benefits of PA on CVD risk via lower body composition scores. Although these observations are in accordance with the literature [18], causality cannot be inferred as increased \%BF may lead to reduced MPA and VPA [22]. The lack of significant associations between PA intensities and blood lipids is in accordance with the literature [12]. Importantly, in adolescents with favourable lipoprotein profile, body composition have been associated to CVD risk [21]. Altogether, our present 
results highlight the important role of PA on cardiovascular health, via negative associations with body composition in this population, independent of blood lipid profile.

In addition to the traditional CVD risk factors, MPA and VPA were significantly related to resting HRV. This is reflected in other studies reporting the associations of combined MVPA and resting HRV in youth $[16,27]$. In contrast to the present results, Radtke, Kriemler, Eser, Saner and Wilhelm (27) did not find associations between VPA and resting HRV in 15 years old adolescents. Discrepancies between the results might lie in the different levels of total MVPA performed by the participants, and different cut-off points used to define PA intensities, as this has been shown to affect the interpretation of PA results [2]. Significant associations between CRF and resting autonomic function were not observed in the present study which is in line with the literature showing no consensus for this relationship $[7,16]$. Interestingly, when CRF was allometrically scaled the positive association between CRF and RMSSD approached significance $(P=0.06)$. As allometric models are superior in controlling for the effect of body size on CRF, this indicates that body size has a confounding effect on the CRF-HRV associations when using the ratio standard method and needs further investigation.

A novel finding in the current study is the significant and negative associations of $H R R \tau$ and $\mathrm{T}_{30}$ to MPA and VPA. These observations show that MPA and VPA are related to neural control of vagal modulation (measured by resting HRV), as well as vagal tonus in adolescents [11]. The group above the median split of VPA, which equated to 2 and 12 min per day for girls and boys respectively, presented faster $\mathrm{RMSSD}_{30}$ with no observed differences between the MPA and CRF groups (see Figure 2). This is the first study to investigate the effects of PA intensity and CRF on parasympathetic reactivation throughout 10 min of recovery. In contrast to MPA and VPA, CRF, LPA and ST had no significant associations with HRR and 
parasympathetic reactivation. As parasympathetic reactivation provides CVD prognostic information $[10,20,25]$, the present results highlights the important role of VPA and novel mechanisms by which this intensity is associated with cardiovascular health in adolescents. Possible explanations for the observed associations are the hemodynamic and hormonal alterations occurring during and after VPA. These alterations may be related to an increased catecholamine response, increased cardiac output, redistribution of blood flow to skin and muscles, and the higher demand on the respiratory muscles amongst others, posing important stresses on the autonomic and cardiovascular systems.

Further to the traditional and non-traditional CVD risk factors, a traditional CVD risk score $\left(\mathrm{CVDR}_{\text {trad }}\right)$ as it is known to differentiate CVD risk in children was used [1]. The observed MPA but not VPA relationship possibly reflects the observed association of MPA to BP which was not found for VPA. Similarly, CRF was negatively and significantly related to $\mathrm{CVDR}_{\text {trad}}$, which is in line with evidence of associations between CVD profile and CRF in youth [29]. However, when CFR was expressed using an allometric model, the observed significance of the relationship disappeared. This observation shows that scaling for body

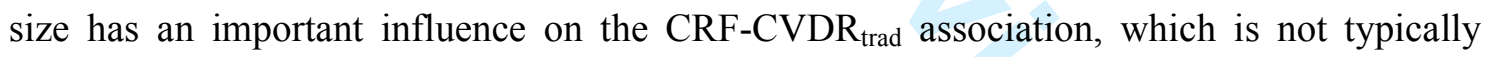
accounted for in the literature [29]. Future studies should account for the confounding effects of body size in youth because CRF normalized by body mass, using a ratio standard approach, might reflect differences in body size occurring during adolescence rather than the ‘true' CRF score.

A recent study has included endothelial function into a CVD risk score in children and examined the associations between MPA, VPA and this new composite CVD score [14]. The authors did not present the changes in the PA relationships to the risk score after the inclusion of endothelial function to the composite risk score so additional explanation could not be 
inferred. In contrast, our current data show that after combining $\operatorname{RMSSD}, \mathrm{T}_{30}$ and $\operatorname{HRR} \tau$ to the $\mathrm{CVDR}_{\text {trad }}$ score, providing a composite risk score $\left(\mathrm{CVDR}_{\text {com }}\right)$, the coefficient of determination rose from 17 to $32 \%$ for MPA and $6 \%$ to $18 \%$ for VPA. This increase in the strength of the association shows that in adolescents, MPA and VPA have important influences on autonomic function. This is in accordance with a recent study showing improvements in HRV but not traditional CVD risk factors in this population following an exercise intervention [4]. Altogether, these results contribute to the possible role of PA on CVD risk in adolescents via autonomic function beyond changes in traditional CVD risk factors.

Some limitations must be considered when interpreting the current findings. For instance, the possible influence of the menstrual cycle in females was not possible to be taken into consideration. Specific types of sedentary behaviours (e.g. TV viewing) were not examined in the current study and the $60 \mathrm{~s}$ epoch used for the PA analyses may have underestimated the PA status of the participants. Additionally, the participants were recruited using a convenience sample and therefore sample bias might be present and the maturation measure applied might have misclassified some of the participants. Finally, the cross-sectional design limits causality between the observed associations.

\section{Conclusions}

This is the first study to examine the associations of PA intensities and CRF to cardiac autonomic function together with traditional CVD risk factors in this population. Complementary to the observed relationships between PA and traditional CVD risk factors, the current study highlights the strong associations of MPA and VPA to autonomic function at rest and recovery in adolescents but not CRF, ST and LPA. Additionally, this is the first study to demonstrate the associations between VPA and a more rapid 10 min parasympathetic reactivation. A two and a threefold increase in the association between MPA, VPA and the 
composite CVD risk score after adding autonomic function to the traditional CVD risk score was observed. These are novel findings that extend the current literature about a potential role of the autonomic function on our understanding of CVD risk reduction. These results provide information for health policy advocating the importance of MPA and VPA during adolescence. Although our study provides original data, longitudinal studies are warranted to clarify the causality of the relationships.

\section{References}

[1] Andersen LB, Riddoch C, Kriemler S, Hills AP. Physical activity and cardiovascular risk factors in children. Br J Sports Med. 2011;45(11):871-6.

[2] Banda JA, Haydel KF, Davila T, Desai M, Bryson S, Haskell WL, Matheson D, Robinson $T N$. Effects of varying epoch lengths, wear time algorithms, and activity cut-points on estimates of child sedentary behavior and physical activity from accelerometer data. PLoS One. 2016;11(3):e0150534.

[3] Berenson GS, Srinivasan SR, Bao W, Newman WP, 3rd, Tracy RE, Wattigney WA. Association between multiple cardiovascular risk factors and atherosclerosis in children and young adults. The Bogalusa Heart Study. N Engl J Med. 1998;338(23):1650-6.

[4] Bond B, Cockcroft EJ, Williams CA, Harris S, Gates PE, Jackman SR, Armstrong N, Barker $A R$. Two weeks of high-intensity interval training improves novel but not traditional cardiovascular disease risk factors in adolescents. Am J Physiol Heart Circ Physiol. 2015;309(6):H1039-47.

[5] Bond B, Williams CA, Barker AR. The reliability of a single protocol to determine endothelial, microvascular and autonomic functions in adolescents. Clin Physiol Funct Imaging. 2016:Ahead of Print.

[6] Bongers BC, De Vries SI, Helders PJM, Takken T. The steep ramp test in healthy children and adolescents: reliability and validity. Med Sci Sports Exerc. 2013;45(2):366-71.

[7] Brunetto AF, Roseguini BT, Silva BM, Hirai DM, Guedes DP. Effects of gender and aerobic fitness on cardiac autonomic responses to head-up tilt in healthy adolescents. Pediatr Cardiol. 2005;26(4):418-24.

[8] Buchheit M, Papelier Y, Laursen PB, Ahmaidi S. Noninvasive assessment of cardiac parasympathetic function: postexercise heart rate recovery or heart rate variability? Am J Physiol Heart Circ Physiol. 2007;293(1):H8-10.

[9] Buchheit M, Platat C, Oujaa M, Simon C. Habitual physical activity, physical fitness and heart rate variability in preadolescents. Int J Sports Med. 2007;28(3):204-10.

[10] Dewey FE, Freeman JV, Engel G, Oviedo R, Abrol N, Ahmed N, Myers J, Froelicher $V F$. Novel predictor of prognosis from exercise stress testing: heart rate variability response to the exercise treadmill test. Am Heart J. 2007;153(2):281-8.

[11] Dewland TA, Androne AS, Lee FA, Lampert RJ, Katz SD. Effect of acetylcholinesterase inhibition with pyridostigmine on cardiac parasympathetic function in sedentary adults and trained athletes. Am J Physiol Heart Circ Physiol. 2007;293(1):H86-92.

[12] Ekelund U, Anderssen SA, Froberg K, Sardinha LB, Andersen LB, Brage S. Independent associations of physical activity and cardiorespiratory fitness with metabolic risk 
factors in children: the European youth heart study. Diabetologia. 2007;50(9):183240 .

[13] Ekelund U, Luan J, Sherar LB, Esliger DW, Griew P, Cooper A. Moderate to vigorous physical activity and sedentary time and cardiometabolic risk factors in children and adolescents. JAMA. 2012;307(7):704-12.

[14] Fussenich LM, Boddy LM, Green DJ, Graves LE, Foweather L, Dagger RM, McWhannell N, Henaghan J, Ridgers ND, Stratton G, Hopkins ND. Physical activity guidelines and cardiovascular risk in children: a cross sectional analysis to determine whether 60 minutes is enough. BMC Public Health. 2016;16(1):67.

[15] Goldberger JJ, Le FK, Lahiri M, Kannankeril PJ, $N g$ J, Kadish AH. Assessment of parasympathetic reactivation after exercise. Am J Physiol Heart Circ Physiol. 2006;290(6):H2446-52.

[16] Gutin B, Howe C, Johnson MH, Humphries MC, Snieder H, Barbeau P. Heart rate variability in adolescents: relations to physical activity, fitness, and adiposity. Med Sci Sports Exerc. 2005;37(11):1856-63.

[17] Imai K, Sato H, Hori M, Kusuoka H, Ozaki H, Yokoyama H, Takeda H, Inoue M, Kamada T. Vagally mediated heart rate recovery after exercise is accelerated in athletes but blunted in patients with chronic heart failure. J Am Coll Cardiol. 1994;24(6):1529-35.

[18] Janssen I, Leblanc AG. Systematic review of the health benefits of physical activity and fitness in school-aged children and youth. Int J Behav Nutr Phys Act. 2010;7:40.

[19] Joyner MJ, Green DJ. Exercise protects the cardiovascular system: effects beyond traditional risk factors. J Physiol. 2009;587(Pt 23):5551-8.

[20] Lahiri MK, Chicos A, Bergner D, Ng J, Banthia S, Wang NC, Subacius H, Kadish AH, Goldberger $J J$. Recovery of heart rate variability and ventricular repolarization indices following exercise. Ann Noninvasive Electrocardiol. 2012;17(4):349-60.

[21] McGill HC, McMahan CA, Zieske AW, Malcom GT, Tracy RE, Strong JP, Group $f t P D o A i Y R$. Effects of nonlipid risk factors on atherosclerosis in youth with a favorable lipoprotein profile. Circulation. 2001;103(11):1546-50.

[22] Metcalf BS, Hosking J, Jeffery AN, Voss LD, Henley W, Wilkin TJ. Fatness leads to inactivity, but inactivity does not lead to fatness: a longitudinal study in children (EarlyBird 45). Arch Dis Child. 2011;96(10):942-7.

[23] Mirwald RL, Baxter-Jones AD, Bailey DA, Beunen GP. An assessment of maturity from anthropometric measurements. Med Sci Sports Exerc. 2002;34(4):689-94.

[24] Mora S, Cook N, Buring JE, Ridker PM, Lee IM. Physical activity and reduced risk of cardiovascular events: potential mediating mechanisms. Circulation. 2007;116(19):2110-8.

[25] Peçanha T, Bartels R, Brito LC, Paula-Ribeiro M, Oliveira RS, Goldberger JJ. Methods of assessment of the post-exercise cardiac autonomic recovery: A methodological review. Int J Cardiol. 2016.

[26] Phillips LR, Parfitt G, Rowlands AV. Calibration of the GENEA accelerometer for assessment of physical activity intensity in children. J Sports Sci Med. 2013;16(2):124-8.

[27] Radtke T, Kriemler S, Eser P, Saner H, Wilhelm M. Physical activity intensity and surrogate markers for cardiovascular health in adolescents. Eur J Appl Physiol. 2013;113(5):1213-22.

[28] Rich C, Geraci M, Griffiths L, Sera F, Dezateux C, Cortina-Borja M. Quality control methods in accelerometer data processing: defining minimum wear time. PLoS One. 2013;8(6):e67206. 
[29] Ruiz JR, Huybrechts I, Cuenca-Garcia M, Artero EG, Labayen I, Meirhaeghe A, Vicente-Rodriguez G, Polito A, Manios Y, Gonzalez-Gross M, Marcos A, Widhalm K, Molnar D, Kafatos A, Sjostrom M, Moreno LA, Castillo MJ, Ortega FB. Cardiorespiratory fitness and ideal cardiovascular health in European adolescents. Heart. 2014;101(10):766-73.

[30] Slaughter MH, Lohman TG, Boileau RA, Horswill CA, Stillman RJ, Loan MDV, Bemben $D A$. Skinfold Equations for Estimation of Body Fatness in Children and Youth. Hum Biol. 1988;60(5):709-23.

[31] Task-Force. Heart rate variability: standards of measurement, physiological interpretation, and clinical use. Circulation. 1996;93(5):1043-65. 
Table 1: Characteristics of the participants according to sex.

Table 2: Fitness and physical activity characteristics of the participants

Table 3: Standardised regression coefficients

Figure 1: Flow chart of recruitment and sample size in the final analysis

Figure 2: Parasympathetic reactivation for the groups above (solid circles) and below (open circles) the sex specific median split of: A) VPA(min $\left.\cdot \mathrm{day}^{-1}\right)$; B) MPA (min $\cdot$ day $\left.^{-1}\right)$; and C) CRF $\left(\mathrm{mL} \cdot \mathrm{kg}^{-0.58} \cdot \mathrm{min}^{-1}\right)$. ${ }^{*} \mathrm{P}<0.05$ for the comparison between groups from 60 to $600 \mathrm{~s}$ (except at $510 \mathrm{~s}, \mathrm{P}=0.053$ ). Values are mean and SD. 
Table 1: Characteristics of the participants according to sex.

\begin{tabular}{rccc}
\hline & All $(\mathrm{n}=53)$ & Female $(\mathrm{n}=23)$ & Male $(\mathrm{n}=31)$ \\
\hline Demographic characteristics & & & \\
Age (y) & $13.1 \pm 0.8$ & $12.9 \pm 0.8$ & $13.1 \pm 0.9$ \\
Stature (cm) & $156.6 \pm 9.6$ & $153.8 \pm 7.8$ & $158.6 \pm 10.5$ \\
Body mass (kg) & $49.2 \pm 12.1$ & $50.1 \pm 13.8$ & $48.5 \pm 11.0$ \\
Pubertal status & & & \\
Pre (n (\%)) & $18(33.3)$ & $1(4)$ & $17(56)$ \\
Circum (n (\%)) & $27(50)$ & $15(65)$ & $12(39)$ \\
Post (n (\%)) & $9(16.7)$ & $7(31)$ & $2(5)$
\end{tabular}

Traditional CVD risk factors

$\begin{array}{rccc}\text { BMI }\left(\mathrm{kg} \cdot \mathrm{m}^{-2}\right) & 19.9 \pm 3.5 & 21.0 \pm 4.3 & 19.1 \pm 2.6 \\ \text { Body fat }(\%) & 20 \pm 7.6 & 23.2 \pm 6.9 & 17.8 \pm 7.4 \\ \text { WC }(\mathrm{cm}) & 68.5 \pm 9.5 & 68.3 \pm 10 & 68.5 \pm 8.9 \\ \text { SPB }(\mathrm{mmHg}) & 113 \pm 9 & 113 \pm 9 & 113 \pm 9 \\ \text { DPB }(\mathrm{mmHg}) & 68 \pm 7 & 70 \pm 7 & 67 \pm 7 \\ \text { TC }\left(\mathrm{mmol} \cdot \mathrm{L}^{-1}\right) & 3.4 \pm 0.5 & 3.4 \pm 0.6 & 3.4 \pm 0.5 \\ \text { HDL }\left(\mathrm{mmol} \cdot \mathrm{L}^{-1}\right) & 1.4 \pm 0.3 & 1.3 \pm 0.4 & 1.4 \pm 0.3 \\ \text { TAG }\left(\mathrm{mmol} \cdot \mathrm{L}^{-1}\right) & 0.7 \pm 0.2 & 0.8 \pm 0.3 & 0.8 \pm 0.5 \\ \text { Glucose }\left(\mathrm{mmol} \cdot \mathrm{L}^{-1}\right) & 4.3 \pm 0.4 & 4.2 \pm 0.5 & 4.3 \pm 0.4\end{array}$

Non-traditional CVD risk factors

$\begin{array}{rccc}\text { RMSSD (ms) } & 77.8 \pm 40.4 & 64.7 \pm 32.4 & 87.6 \pm 43.4 \\ \text { HF (ln) } & 7.8 \pm 1.1 & 7.5 \pm 1.1 & 8.0 \pm 1.0 \\ \text { LF (ln) } & 7.1 \pm 0.9 & 6.8 \pm 0.9 & 7.4 \pm 0.9 \\ \text { HF (nu) } & 64.9 \pm 16.2 & 65.2 \pm 15.4 & 64.7 \pm 17.0 \\ \text { LF (nu) } & 34.8 \pm 16.2 & 34.6 \pm 15.4 & 34.9 \pm 17.0 \\ \text { LF/HF } & 0.7 \pm 0.7 & 0.6 \pm 0.5 & 0.7 \pm 0.9 \\ \mathrm{~T}_{30}(\mathrm{~s}) & 192 \pm 88.8 & 193.3 \pm 57.5 & 191.1 \pm 107.4 \\ \text { HRR } \tau(\mathrm{s}) & 70.8 \pm 29.6 & 66.1 \pm 15.8 & 74.4 \pm 36.5\end{array}$

BMI, body mass index; WC, waist circumference; SPB, systolic blood pressure; DBP, diastolic blood pressure; TC, total cholesterol; HDL, high-density lipoprotein; TAG, triglycerides; RMSSD, square root of the mean of the sum of the squares of differences between adjacent RR intervals; HF, High-frequency; LF, Low-frequency. 
Table 2: Fitness and physical activity characteristics of the participants

\begin{tabular}{rccc}
\hline & All $(\mathrm{n}=54)$ & Girls $(\mathrm{n}=22)$ & Boys $(\mathrm{n}=31)$ \\
\hline $\mathrm{CRF}\left(\mathrm{mL} \cdot \mathrm{kg}^{-1} \cdot \mathrm{min}^{-1}\right)$ & $46.3 \pm 8.1$ & $42.5 \pm 9.2$ & $49.2 \pm 5.9$ \\
$\mathrm{CRF}\left(\mathrm{mL} \cdot \mathrm{kg}^{-0.58} \cdot \mathrm{min}^{-1}\right)$ & $235.1 \pm 36.1$ & $215.9 \pm 35.9$ & $249.4 \pm 29.3$ \\
$\mathrm{ST}\left(\mathrm{min} \cdot \mathrm{day}^{-1}\right)$ & $329.6 \pm 110.4$ & $330.7 \pm 105.5$ & $328.9 \pm 115.7$ \\
LPA $\left(\mathrm{min} \cdot \mathrm{day}^{-1}\right)$ & $278.7 \pm 112.2$ & $305.2 \pm 104.7$ & $259.1 \pm 115.2$ \\
MPA (min $\cdot$ day $\left.^{-1}\right)$ & $104.6 \pm 33.4$ & $92.0 \pm 36.0$ & $114.0 \pm 28.5$ \\
VPA (min $\cdot$ day $\left.^{-1}\right)$ & $11.2 \pm 10.4$ & $5.5 \pm 6.3$ & $15.4 \pm 11.0$ \\
MVPA (min $\cdot$ day $\left.^{-1}\right)$ & $115.8 \pm 41.1$ & $97.6 \pm 39.8$ & $129.4 \pm 37.2$ \\
\hline
\end{tabular}

CRF, cardiorespiratory fitness; ST, sedentary time; LPA, light physical activity; MPA, moderate physical activity; VPA, vigorous physical activity; MVPA, moderate to vigorous physical activity.

Georg Thieme Verlag KG. P. O. Box 3011 20, D-70451 Stuttgart, Germany. http://www.thieme.de/fz/sportsmed/index.html 
Table 3: Standardised regression coefficients

\begin{tabular}{|c|c|c|c|c|c|c|c|c|c|c|c|c|}
\hline & $\mathrm{ST}\left(\min \cdot \mathrm{day}^{-1}\right)$ & & 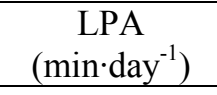 & & 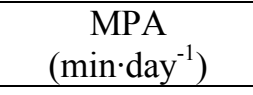 & & 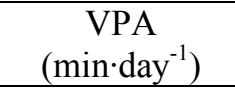 & & $\begin{array}{c}\mathrm{CRF} \\
\left(\mathrm{ml} \cdot \mathrm{kg} \cdot \mathrm{min}^{-1}\right) \\
\end{array}$ & & $\begin{array}{c}\mathrm{CRF} \\
\left(\mathrm{ml} \cdot \mathrm{kg}^{-0.58} \cdot \mathrm{min}^{-1}\right)\end{array}$ & \\
\hline $\begin{array}{l}\text { Traditional CVD } \\
\text { risk factors }\end{array}$ & $\beta(P)$ & $r^{2}$ & $\beta(P)$ & $r^{2}$ & $\beta(P)$ & $r^{2}$ & $\beta(P)$ & $\mathrm{r}^{2}$ & $\beta(P)$ & $r^{2}$ & $\beta(P)$ & $r^{2}$ \\
\hline $\mathrm{BMI}\left(\mathrm{kg} \cdot \mathrm{m}^{2}\right)$ & $-0.017(0.90)$ & 0.01 & $0.029(0.83)$ & 0.01 & $-0.276(0.04)$ & 0.07 & $-0.229(0.15)$ & 0.03 & $-0.706(<0.001)$ & 0.41 & $-0.430(0.004)$ & 0.13 \\
\hline$\% \mathrm{BF}(\%)$ & $0.022(0.86)$ & 0.01 & $0.024(0.85)$ & 0.01 & $-0.310(0.02)$ & 0.09 & $-0.384(0.01)$ & 0.10 & $-0.701(<0.001)$ & 0.40 & $-0.602(<0.001)$ & 0.25 \\
\hline $\mathrm{WC}(\mathrm{cm})$ & $-0.050(0.72)$ & 0.01 & $0.091(0.52)$ & 0.01 & $-0.316(0.03)$ & 0.09 & $-0.300(0.07)$ & 0.06 & $-0.765(<0.001)$ & 0.48 & $-0.496(0.001)$ & 0.17 \\
\hline MAP (mmHg) & $-0.023(0.87)$ & 0.01 & $0.142(0.30)$ & 0.02 & $-0.326(0.02)$ & 0.09 & $0.182(0.27)$ & 0.02 & $-0.191(0.20)$ & 0.03 & $-0.170(0.29)$ & 0.02 \\
\hline $\mathrm{TC}\left(\mathrm{mmol} \cdot \mathrm{L}^{-1}\right)$ & $0.062(0.66)$ & 0.01 & $0.062(0.66)$ & 0.03 & $0.041(0.78)$ & 0.01 & $-0.162(0.34)$ & 0.02 & $-0.09(0.56)$ & 0.01 & $-0.236(0.15)$ & 0.04 \\
\hline $\mathrm{HDL}\left(\mathrm{mmol} \cdot \mathrm{L}^{-1}\right)$ & $0.177(0.20)$ & 0.03 & $-0.169(0.23)$ & 0.02 & $0.209(0.15)$ & 0.04 & $0.037(0.83)$ & 0.01 & $0.138(0.37)$ & 0.02 & $-0.026(0.87)$ & 0.01 \\
\hline $\mathrm{TAG}\left(\mathrm{mmol} \cdot \mathrm{L}^{-1}\right)$ & $-0.145(0.28)$ & 0.02 & $-0.024(0.86)$ & 0.01 & $-0.158(0.26)$ & 0.02 & $-0.204(0.22)$ & 0.03 & $-0.135(0.37)$ & 0.01 & $-0.08(0.63)$ & 0.01 \\
\hline $\begin{array}{r}\text { Glucose } \\
\left(\mathrm{mmol} \cdot \mathrm{L}^{-1}\right)\end{array}$ & $-0.106(0.45)$ & 0.01 & $-0.046(0.75)$ & 0.01 & $-0.184(0.21)$ & 0.03 & $-0.165(0.34)$ & 0.02 & $-0.189(0.22)$ & 0.03 & $-0.097(0.57)$ & 0.01 \\
\hline $\begin{array}{l}\text { Non-traditional } \\
\text { CVD risk factors }\end{array}$ & & & & & & & & & & & & \\
\hline RMSSD (ms) & $-0.005(0.97)$ & 0.01 & $0.006(0.96)$ & 0.01 & $0.402(0.003)$ & 0.14 & $0.453(0.005)$ & 0.13 & $0.237(0.11)$ & 0.05 & $0.299(0.06)$ & 0.06 \\
\hline $\operatorname{HRR} \tau(\mathrm{s})$ & $-0.139(0.33)$ & 0.02 & $0.149(0.30)$ & 0.02 & $-0.311(0.03)$ & 0.08 & $-0.406(0.02)$ & 0.11 & $-0.034(0.83)$ & 0.01 & $0.109(0.22)$ & 0.01 \\
\hline $\mathrm{T}_{30}(\mathrm{~s})$ & $-0.111(0.42)$ & 0.02 & $0.100(0.49)$ & 0.01 & $-0.356(0.02)$ & 0.11 & $-0.433(0.01)$ & 0.12 & $0.081(0.61)$ & 0.01 & $0.207(0.22)$ & 0.03 \\
\hline $\begin{array}{l}\text { Clustered CVD } \\
\text { risk scores }\end{array}$ & & & & & & & & & & & & \\
\hline $\mathrm{CVDR}_{\text {trad }}$ & $-0.152(0.28)$ & 0.02 & $0.041(0.78)$ & 0.01 & $-0.447(0.002)$ & 0.17 & $-0.340(0.08)$ & 0.06 & $-0.438(0.004)$ & 0.15 & $-0.277(0.11)$ & 0.05 \\
\hline $\mathrm{CVDR}_{\text {auto }}$ & $-0.115(0.42)$ & 0.01 & $0.102(0.48)$ & 0.01 & $-0.483(0.001)$ & 0.20 & $-0.563(0.001)$ & 0.20 & $-0.070(0.67)$ & 0.01 & $0.020(0.91)$ & 0.01 \\
\hline $\mathrm{CVDR}_{\text {com }}$ & $-0.142(0.32)$ & 0.02 & $0.041(0.78)$ & 0.01 & $-0.601(<0.001)$ & 0.32 & $-0.540(0.001)$ & 0.18 & $-0.313(0.05)$ & 0.08 & $-0.153(0.38)$ & 0.02 \\
\hline
\end{tabular}

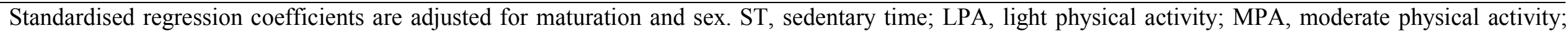

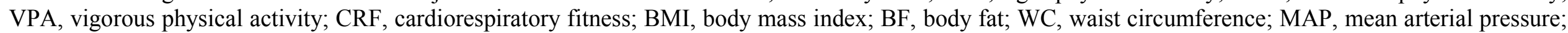

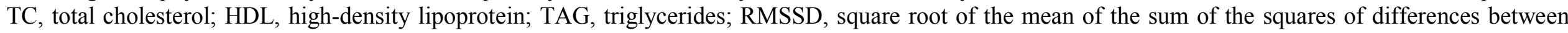
adjacent RR intervals; 
Figure 1: Flow chart of recruitment and sample size in the final analysis the final number of participan $338 \times 190 \mathrm{~mm}(230 \times 230 \mathrm{DPI})$ 
Figure 2: Parasympathetic reactivation for the groups above (solid circles) and below (open circles) the sex specific median split of: A) VPA(min-day-1); B) MPA (min.day-1); and C) CRF (mL $\cdot \mathrm{kg}-0.58 \cdot \mathrm{min}-1)$. $* \mathrm{P}<0.05$ for the comparison between groups from 60 to $600 \mathrm{~s}$ (except at $510 \mathrm{~s}, \mathrm{P}=0.053$ ). Values are mean and SD. The time course of parasympath $211 \times 446 \mathrm{~mm}(300 \times 300 \mathrm{DPI})$ 